\title{
Annealing effects on the Interband Transition and Optical constants of cobalt doped Cadmium oxide Thin Films
}

\author{
Nadir Fadhil Habubi \\ Al_Mustansiriyah University, College of Education, Physics Department, Baghdad, (IRAQ) \\ E-mail: nadirfadhil@yahoo.com
}

\begin{abstract}
The CdO: Co films have been deposited on substrate temperature at $400{ }^{\circ} \mathrm{C}$ by spray pyrolysis method using cadmium chloride and cobalt chloride as a precursors for $\mathrm{Cd}$ and $\mathrm{Co}$ ions, respectively. The effect of annealing temperature on optical constants of $\mathrm{Co}$ : $\mathrm{CdO}$ thin films are investigated using UV-Visible spectrophotometer in the range of (300-900) $\mathrm{nm}$ at room temperature. The absorbance and optical parameters such as $\alpha, \mathrm{n}, \varepsilon_{1}, \varepsilon_{2}$, and $\chi$ are increased when the annealing temperature increases, while the energy gap decreased from $2.5 \mathrm{eV}$ before annealing to $2.48 \mathrm{eV}$ after $500{ }^{\circ} \mathrm{C}$ annealing temperature. Urbach energy is increased with the increasing of annealing temperature from $353 \mathrm{meV}$ for sample before annealing to $715 \mathrm{meV}$ for the same samples annealed at $500{ }^{\circ} \mathrm{C}$.
\end{abstract}

Key words: Co doped $\mathrm{CdO}$, Optical properties, annealing temperature.

\section{Introduction}

$\mathrm{CdO}$ thin films present low resistivity. Studies have been made however with the objective of decreasing the resistivity even further and getting more stable films. CdO films have been doped with different impurities such as indium, copper, tin and fluorine $(\mathrm{F})^{[1-3]}$, and annealed in different controlled atmospheres. Resistivity values around $10^{-4} \Omega \mathrm{cm}$ can be obtained ${ }^{[4-6]}$.

Enhancing the electrical properties of transparent conducting oxides(TCOs), specially conductivity, can be done either by increasing the charge carrier concentration or by improving the mobility of those carriers.Increasing carrier concentration can be achieved by heavy doping of the TCO materials. This will,however, degrade the transparency due to increased free carrier absorption ${ }^{[7]}$,

Among these transparent conducting oxides, cadmium oxide $(\mathrm{CdO})$ has received a considerable attention for solar cell application due to its low electrical resistivity and high transparency in the visible range of solar spectrum ${ }^{[8]}$.

Cadmium oxide thin films prepared by various techniques, spray pyrolysis ${ }^{[9-11]}$, ion beam sputtering ${ }^{[11]}$, chemical bath deposition ${ }^{[12]}$, activated reactive evaporation ${ }^{[13]}$, thermal oxidation ${ }^{[14]}$, reactive sputtering ${ }^{[15-16]}$ and sol-gel ${ }^{[17]}$.

The aim of this study is to study the effect of annealing temperature on the interband transition and optical constants of $\mathrm{CdO}$ thin film that doped by $1 \% \mathrm{Co}$, utilizing chemical spray pyrolysis technique. 


\section{Experimental Details}

Co doped $\mathrm{CdO}$ thin films were prepared by chemical pyrolysis method. The Cadmium chloride supplied from (BDH Chemicals Laboratory, England) with $0.1 \mathrm{M}$ dissolved in redistilled water, and doped by $1 \%$ Cobalt . The optimization conditions were arrived at the following : spray time was $8 \mathrm{~s}$ followed by $2 \mathrm{~min}$ to avoid the excessive cooling, the carrier gas (filtered compressed air) was maintained at a pressure of $10^{5}$ Pascal, distance between nozzle and substrate was about $29 \mathrm{~cm}$, and the solution flow rate was $5 \mathrm{ml} / \mathrm{min}$. These prepared films are deposited on glass substrates at a temperature of $400{ }^{\circ} \mathrm{C}$.

Gravimetric method was used to determine the film thickness, which to be $350 \pm 30 \mathrm{~nm}$, and the UV-VIS spectrophotometer with a double beam (Shimadzu UV-VIS Japan) was used for recording the optical transmittance with a wavelength range of (300-900) $\mathrm{nm}$. The as deposited samples were exposed to 2 hours annealing temperature of 450 and $500{ }^{\circ} \mathrm{C}$ respectively.

\section{Results and Discussions}

The optical properties of $\mathrm{Co}$ doped $\mathrm{CdO}$ thin film are determined by recording absorption spectra by UV-Visible spectrophotometer in the range of (300-900) $\mathrm{nm}$ at room temperature. Fig. 1 represent the relationship between the absorbance versus wavelength. From this figure, it can show that the absorbance increased with increasing annealing temperature, the absorption edge was shifted to lower wavelength (blue shift) as the annealing temperature increases

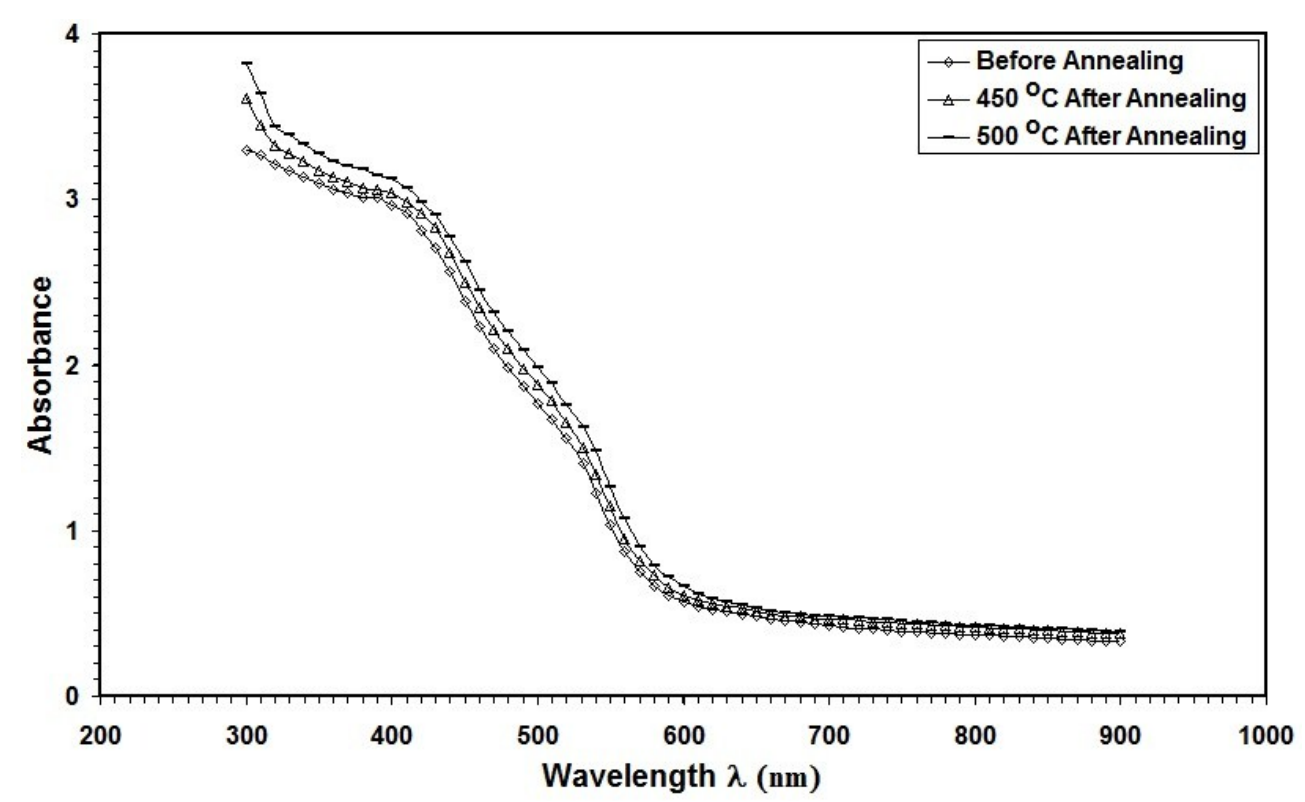

Fig. 1 Variations of absorbance as a function of wavelength.

The absorption coefficient $(\alpha)$ was calculated from the transmittance spectra using the relation [18]: 
$\alpha=\frac{\ln (1 / T)}{d}$

Where (T) is the transmittance and (d) is the film thickness. The variation of absorption coefficient versus wavelength is shown in Fig. 2. From this figure, it can notice that the absorption coefficient increased with increasing annealing temperature. This results an be explained according to an increase in order of crystallinity as the annealing temperatures increased

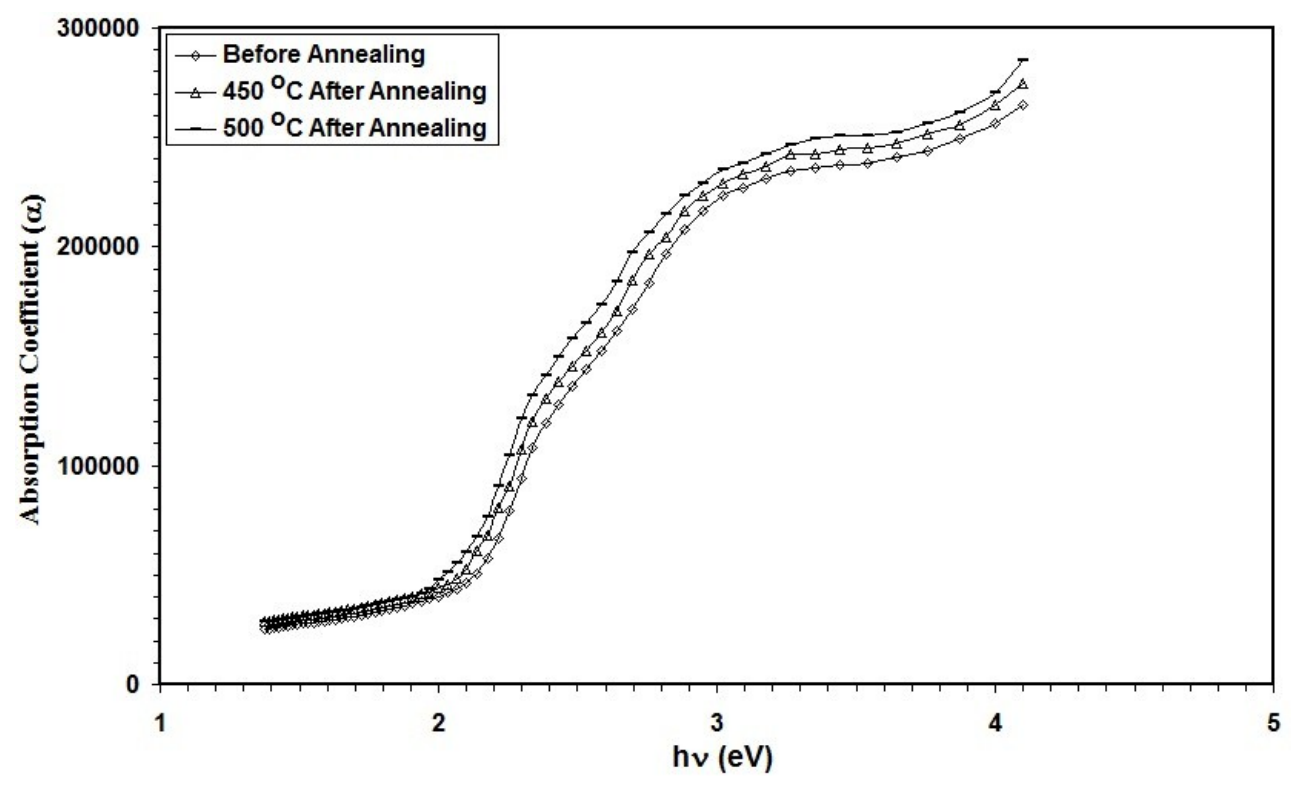

Fig. 2. Variation of absorption coefficient as a function of wavelength.

The relationship between absorption coefficient and the optical band gap is expressed to calculate the band gap by the following relationship ${ }^{[19]}$ :

$\alpha h v=A(h v-E g)^{m}$

Where $\mathrm{A}$ is an energy-independent constant and $\mathrm{Eg}$ is the optical band gap and $\mathrm{m}$ is a constant which determined type of optical transition. The direct forbidden energy band gap was calculated from the plot $(\alpha h v)^{2}$ versus $h v$, and by extrapolation the linear portion of the curves until they intercept the photon energy axis as shown in Figs. (4-6). From these figures, it can be noticed that there is a increasing in energy gap with the increasing of annealing temperature. This might be interpreted as the relation between crystallite size and the optical energy gap ${ }^{[20]}$. 


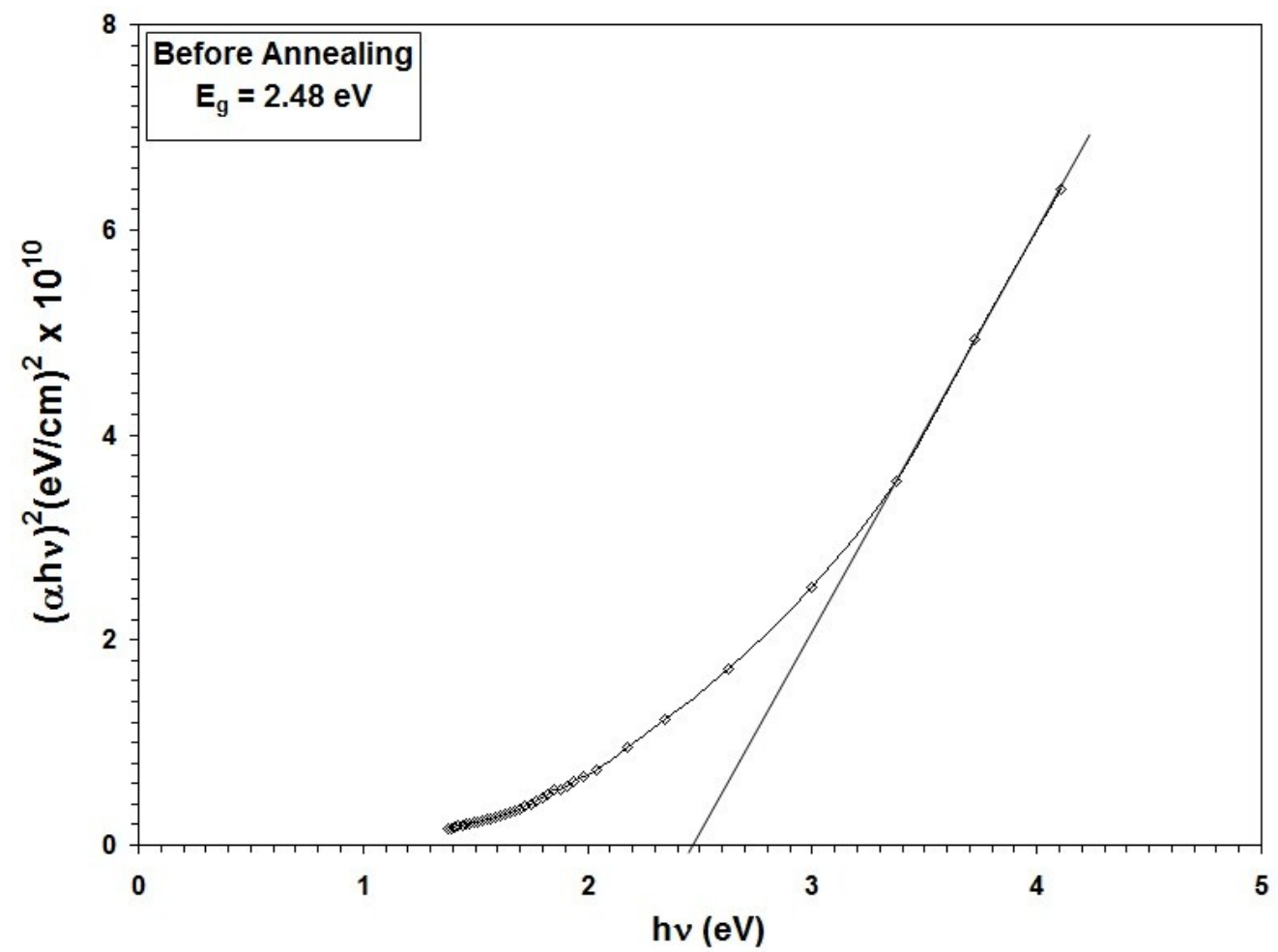

Fig. $4(\alpha h v)^{2}$ vs. hv plot of Co:CdO thin film before annealing.

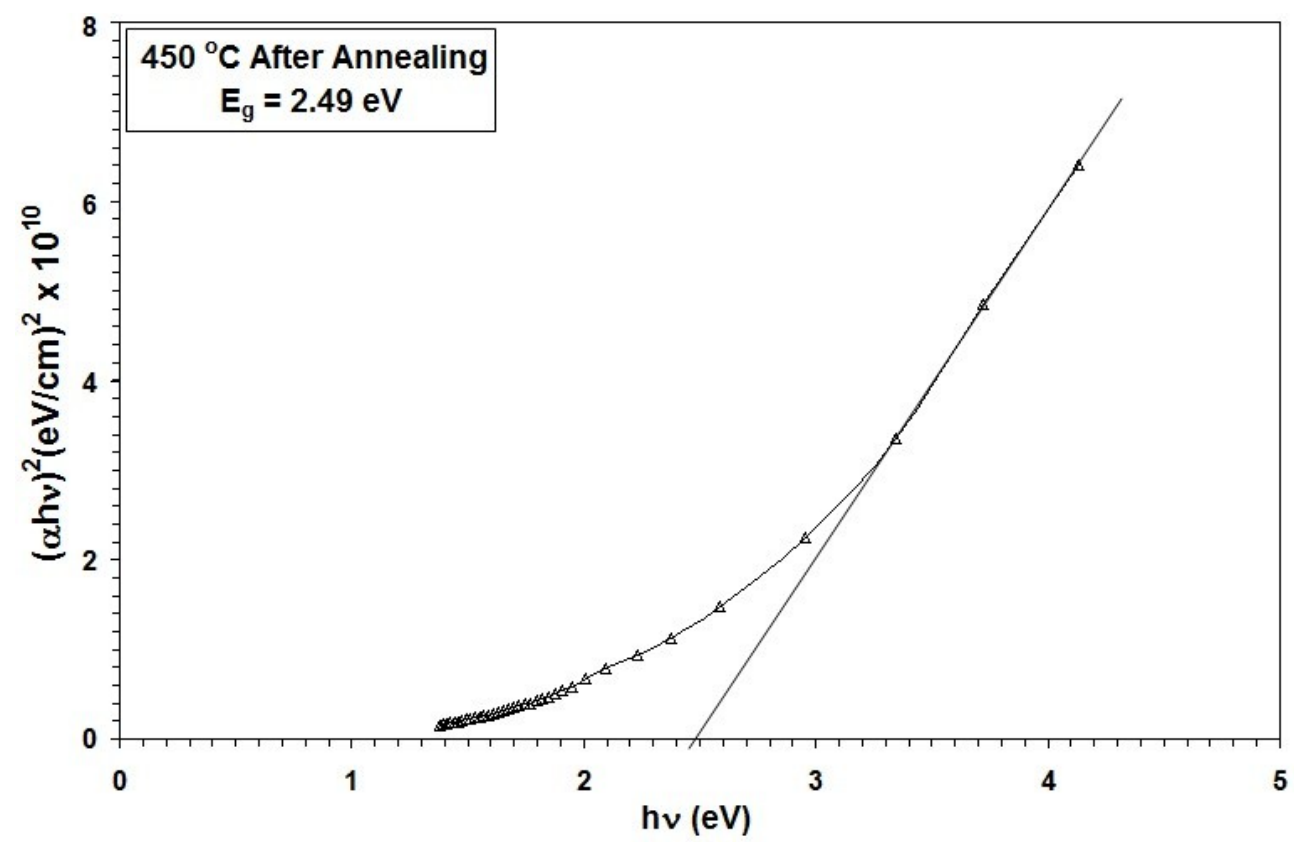

Fig. $5(\alpha h v)^{2} v s . h v$ plot of $\mathrm{Co}: \mathrm{CdO}$ thin film at annealing temperature of $450{ }^{\circ} \mathrm{C}$. 


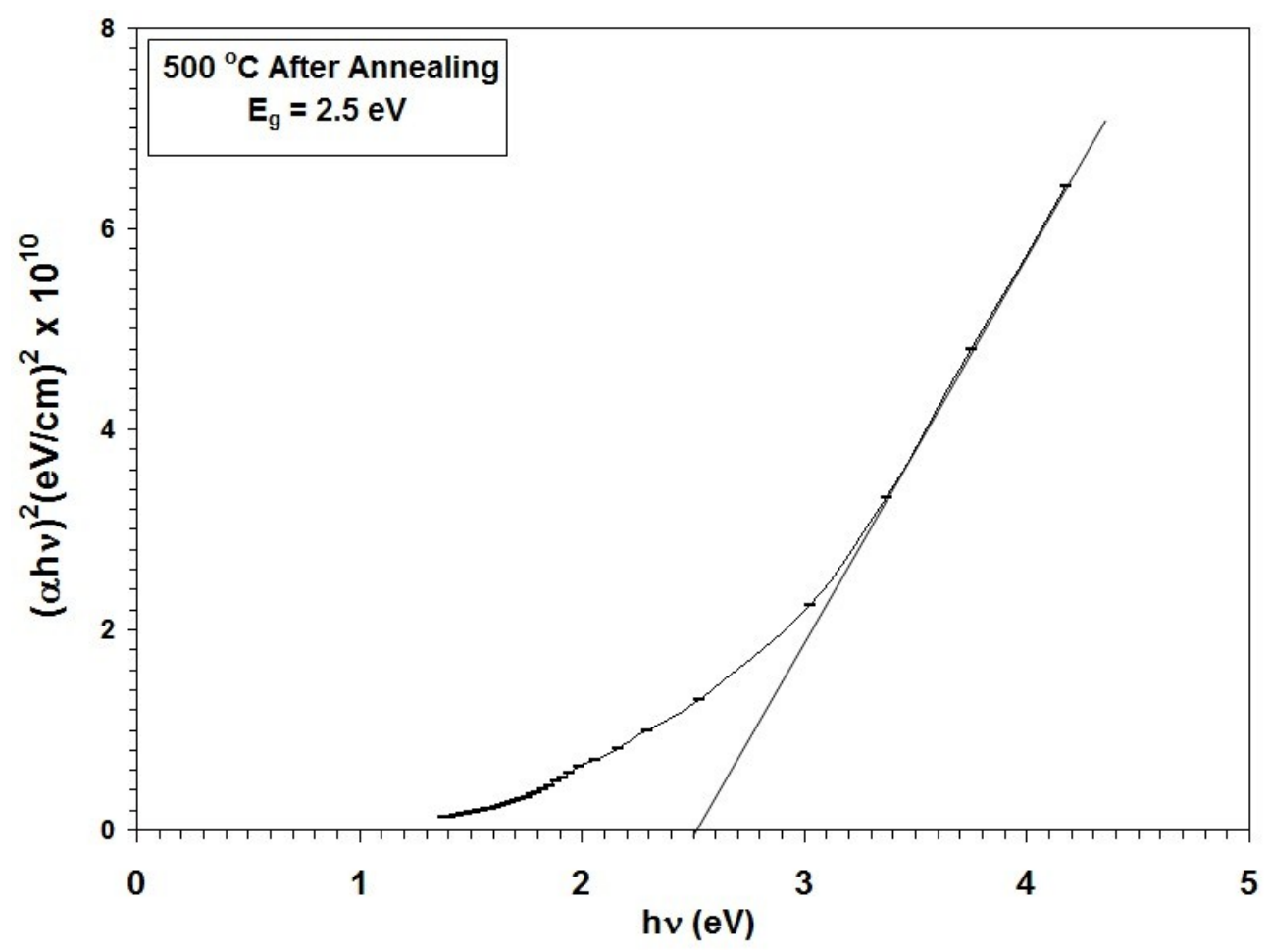

Fig. $6(\alpha h v)^{2}$ vs. hv plot of $\mathrm{Co}: \mathrm{CdO}$ thin film at annealing temperature of $500{ }^{\circ} \mathrm{C}$.

The width of the localized states available in the optical bandgap affects the optical bandgap structure and optical transitions and it is called as Urbach tail, which could be determined by the following relation ${ }^{[21]}$ :

$\alpha=\alpha_{0} \exp \left[\frac{E}{E_{U}}\right]$

Where $\mathrm{E}$ is the photon energy, $\left(\alpha_{0}\right)$ is constant, and $\mathrm{E}_{\mathrm{U}}$ is the Urbach energy which refers the width of the exponential absorption edge. Fig.7 represent $\ln \alpha$ as a function of photon energy (hv). Urbach energy, decreased with increasing annealing temperature from $715 \mathrm{eV}$ before annealing to $335 \mathrm{eV}$ after annealing by $500^{\circ} \mathrm{C}$. 


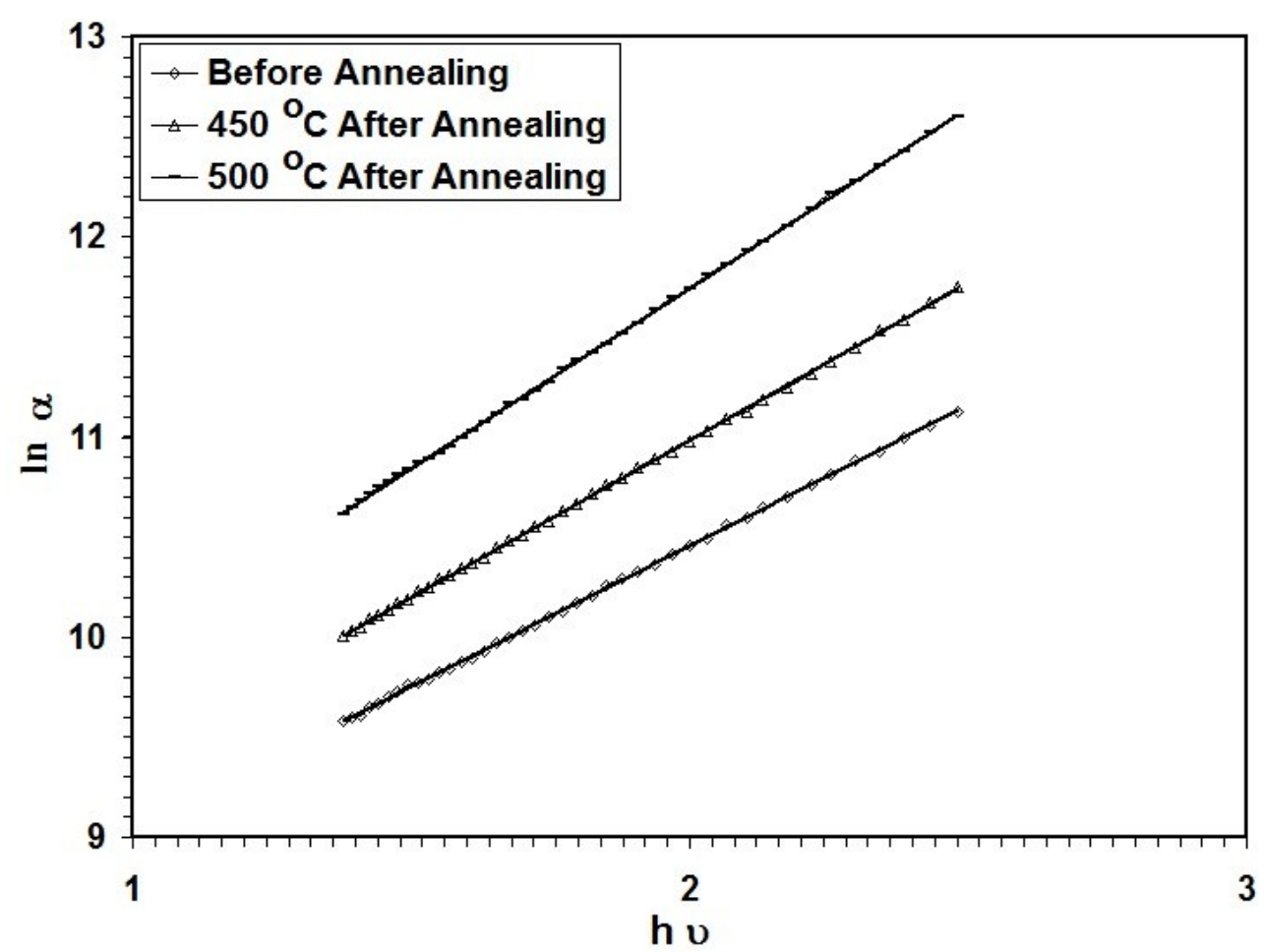

Figure 7: $\ln \alpha$ as a function of hv.

The refractive index of the samples can be obtained from the following equation ${ }^{[22]}$.

$$
n=\left(\frac{1+R}{1-R}\right)+\sqrt{\frac{4 R}{(1-R)^{2}}-k^{2}}
$$

Where $\mathrm{k}$ is the extinction coefficient. The refractive index values as a function of wavelength, before and after the annealing treatment, are shown in Fig. 8, and it can notice the increasing of refractive index when the annealing temperature increases for prepared thin film.

The real and imaginary parts of complex dielectric constant are expressed as ${ }^{[23]}$ :

$$
\begin{aligned}
& \varepsilon_{1}=\mathrm{n}^{2}-\mathrm{k}^{2} \\
& \varepsilon_{2}=2 \mathrm{nk}
\end{aligned}
$$

Where $\varepsilon_{1}$ is the real part and $\varepsilon_{2}$ is the imaginary part of the dielectric constant. The dependence of the real $\left(\varepsilon_{1}\right)$ and imaginary $\left(\varepsilon_{2}\right)$ parts of the dielectric constant on photon energy are shown in Figs. $(9,10)$. From these figures it can notice that the real and imaginary parts of dielectric constants increase with increasing annealing temperature, and it can show the peaks in the wavelength at $550 \mathrm{~nm}$ for all prepared thin films. 


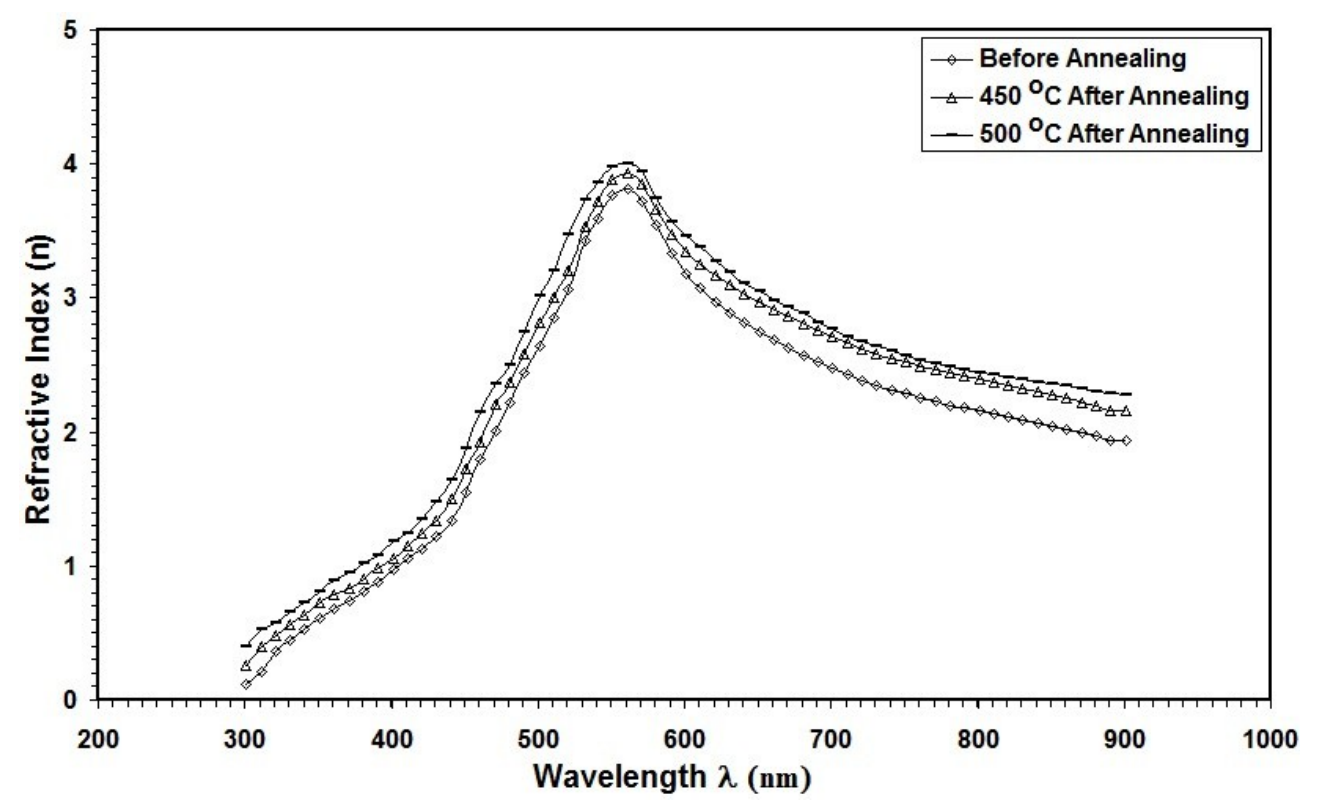

Fig. 8 Variation of refractive index as a function of wavelength.

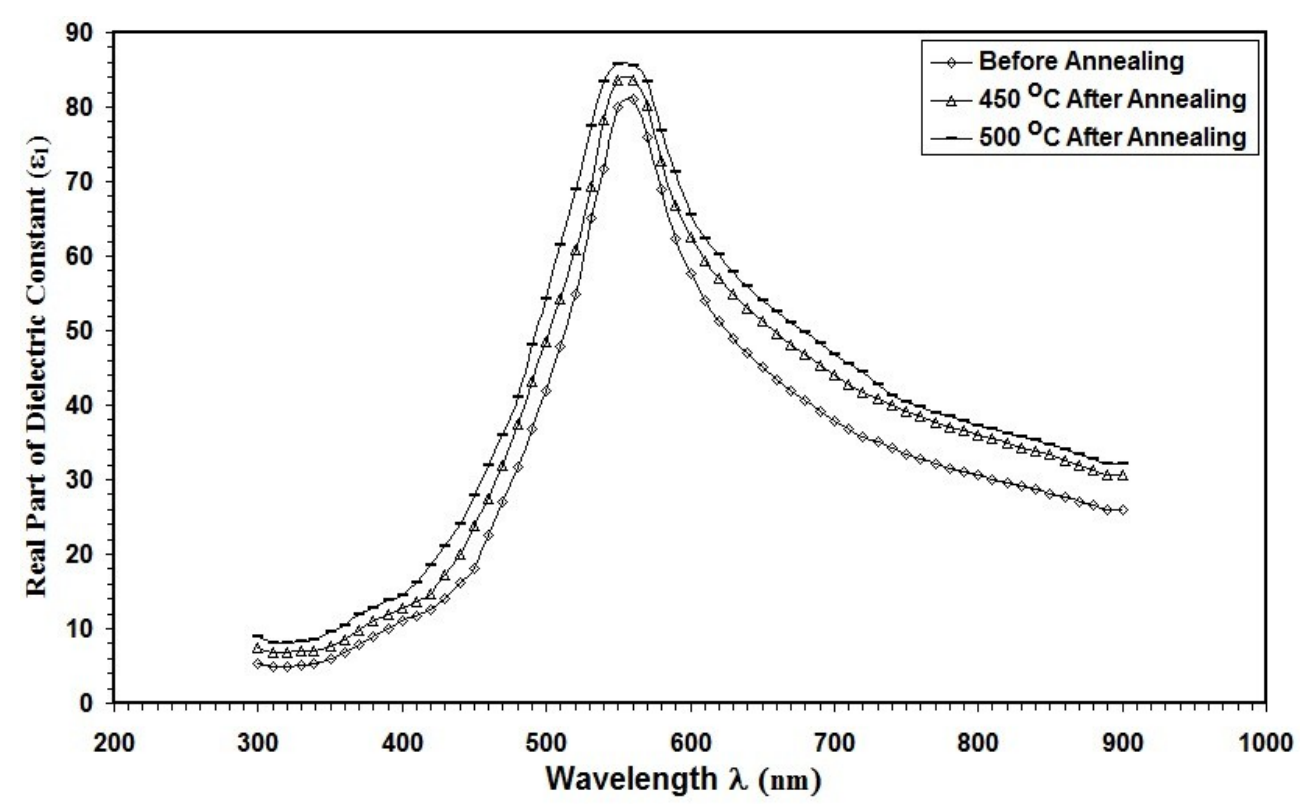

Fig. 9 Variation of real part of dielectric constant as a function of wavelength. 


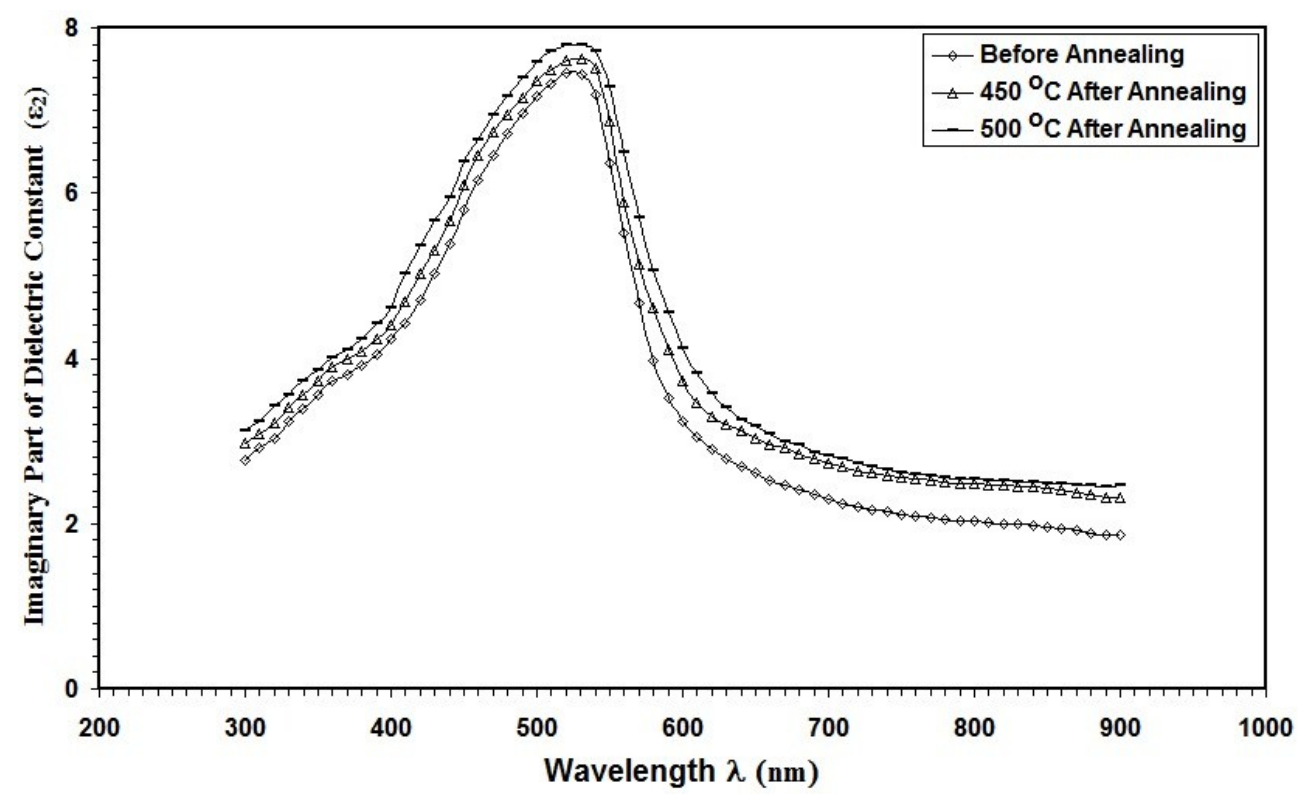

Fig. 10 Variation of imaginary part of dielectric constant as a function of wavelength.

The skin depth $(\chi)$ could be calculated using the following relation ${ }^{[24]}$.

$$
\chi=\frac{\lambda}{2 \pi K}
$$

Where $\lambda$ is the wavelength of the incident photon and $\mathrm{K}$ is the extinction coefficient.

Fig. 11 represent the relationship between skin depth versus wavelength. From this figure, it can be noticed that the skin depth increased with increasing annealing temperature, so the skin depth is transmittance related.

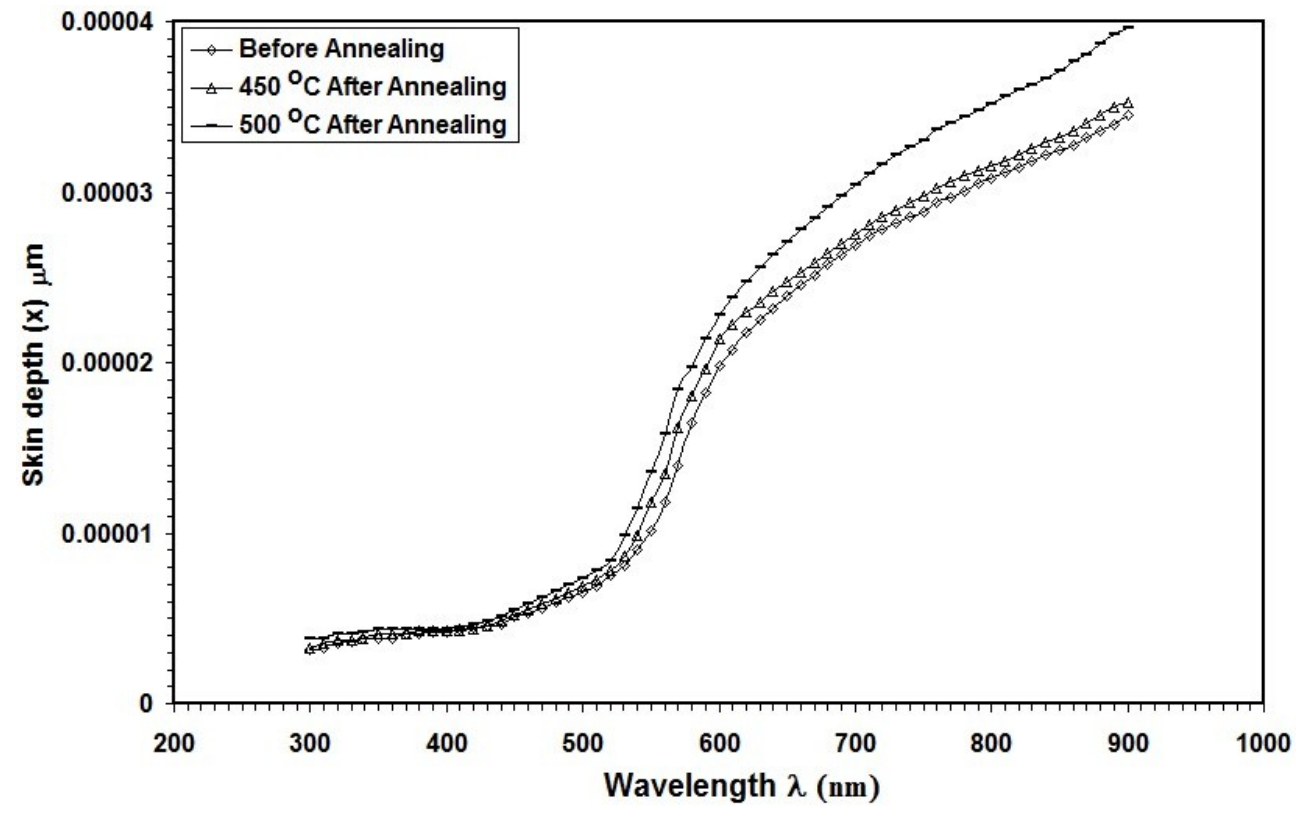

Fig. 11. Variation of skin depth as a function of wavelength. 


\section{Conclusions}

The optical properties of $\mathrm{Co}: \mathrm{CdO}$ thin film is studied for various annealing temperature that deposited on a glass substrate $\left(400{ }^{\circ} \mathrm{C}\right)$ by chemical pyrolysis method. The energy gap is shifted towards the higher energies when the annealing temperature increases to $500{ }^{\circ} \mathrm{C}$.The absorbance and optical parameters such as $\alpha, \mathrm{n}, \varepsilon_{1}, \varepsilon_{2}$, and $\chi$ are increased as the annealing temperature increases.

\section{References}

[1] T.K. Lakshmanan, J. Electrochem. Soc. 110 (1963) 548.

[2] R. Ferro, J.A. Rodríguez, Thin Solid Films 347 (1999) 295.

[3] Zhiyong Zhao, D.L. Morel, C.S. Ferekides, Thin Solid Films 413 (2002)203.

[4] K. Gurumurugan, D. Mangalaraj, Sa.K. Narayandass, J. Electron. Mater. 25 (1996) 765.

[5] N. Ueda, H. Maeda, H. Ozono, H. Kawazoe, J. Appl. Phys. 84 (1998) 6174.

[6] D. Ma, Z. Ye, L. Wang, J. Huang, B. Zhao, Mater. Lett. 58 (2004) 128.

[7] H. Kim, J. Horwitz, W. Kim, A. Makinen, Z. Kafafi, D. Chrisey, Thin SolidFilms 420 (2002) 539.

[8] Y. Yang, L. Wang, H. Yan, S. Jin, T.J. Marksa, S. Li, Appl. Phys. Lett. 89 (2006) 051116.

[9] K.Gurumurugan, D.Mangalaraj, Sa.K.Narayandass, C. Balasubramanian, Phys.Stat.Sol.(a)143 (1994) 85.

[10]K.Gurumurugan, D.Mangalaraj, Sa.K.Narayandass, K.Sekar,C.P.G. Vallabhan, Semicond. Sci. Technol. 9 (1994) 1827.

[11]T.L.Chu, S.S.Chu, J.Electron.Mater. 19 (1990) 1003.

[12]M.Ocampo, P.J.Sebastian, J.Campos, Phys.Stat.Sol.(a)143 (1994) K29.

[13]G.Phatak, R.Lal, Thin Solid Films 245 (1994) 17.

[14] I.J. Ferrer, Electrochim. Acta 38 (1993) 2199.

[15] K.Gurumurugan, D.Mangalaraj, Sa.K.Narayandass, J. Electron. Mater. 25 (1996) 765.

[16] T.K. Subramanyam, S. Uthanna, B.S. Naidu, Physica Scripta 57 (1998) 317.

[17] D.M. Carballeda-Galicia, R. Castanedo-Perez, O. Jimenez- "' Sandoval, S.JimenezSandoval, G.Torres-Delgado, C.I.Zuni-ga-Romero, Thin Solid Films 317 (2000) 105.

[18] Xue S. W., Zu X. T., Zhou W. L., Deng H-X., Xiang X., Zhang L., and Deng H., "Effects of PostThermal Annealing on The Optical Constants of ZnO Thin Film", Journal of Alloys and Compounds, 448 (2008) 21.

[19] N. F. Mott, E. A. Davis, Electronic Process in Non-Crystalline Materials, Calendron Press, Oxford (1979). 
[20]Caglar, Y., Ilican, S., Caglar, M. and Yakuphanoglu, F. ,"Effects of In, Al and Sn Dopants on The Structural and Optical Properties of $\mathrm{ZnO}$ Thin Films", SpectrochimicaActa Part A, 67 (2007) 1113.

[21] P.K. Ghosh, R. Maity, K.K. Chattopadhyay, Sol. Energy Mater. Sol. Cells 81 (2004) 279.

[22] S. K. J. Al-Ani, Y. Al-Ramadin, M. S. Ahmad, A. M. Zihlif, M. Volpe, M. Malineonico, E. Martuscelli, G. Ragosta, Polymer Testing, 18 (1999) 611.

[23] E. Abd El-Wahabb, A. E. Bekheet, Applied Surface Science, 173 (2001) 103.

[24] Eloy, J. F. Power Lasers, National School of Physics, Grenoble, France, John Wiley and Sons, 59 (1984). 